\title{
Espacialización, alterización y bienestar en el Barrio Toba de la ciudad de Resistencia, Argentina
}

\author{
Cecilia Quevedo \\ Instituto de Estudios en Comunicación, Expresión y Tecnologías \\ Universidad Nacional de Córdoba, Córdoba, Argentina \\ quevedoceci@gmail.com
}

\begin{abstract}
RESUMEN
Desde la década de 1950, en el norte argentino se incrementó el despojo de poblaciones indígenas en regiones rurales del interior provincial que conllevaron a relocalizaciones de esos grupos sociales en contextos urbanos. El artículo analiza los procesos de espacialización y alterización sobre la población indígena de la etnia toba (qom) a partir de la construcción de viviendas sociales en el Barrio Toba de la ciudad de Resistencia (provincia de Chaco, Argentina). El objetivo del trabajo problematiza las modalidades ideológicas a partir de las cuales la población indígena desproletarizada en ingenios y colonial algodoneras adviene progresivamente como objeto de control en paralelo a los procesos de modernización de la ciudad de Resistencia y las valoraciones estetizantes de la hegemonía político-cultural de una nueva provincianía. El argumento central sostiene que, durante los ańos sesenta y setenta, el Barrio Toba operó como escenario de subordinación integracionista en una ciudad que se embellecía desde la herencia cultural europea. Para alcanzar este propósito metodológicamente se utilizan fuentes documentales y periodísticas, entrevistas e imágenes. Como resultado, reflexiona sobre las nociones subalternas de bienestar y los mecanismos de incorporación emergentes respecto al indígena como subjetividad productiva, política y urbanizada.
\end{abstract}

Palabras clave: Crisol de razas, indígenas, integracionismo, modernización urbana, trabajo, vivienda

\section{Spatialization, alteration and well-being in the Toba neighborhood in the city of Resistencia, Argentina}

\begin{abstract}
Since the 1950s, in Northern Argentina the dispossession of indigenous populations in rural regions of the interior of the was increased, leading to the relocation of these social groups in urban contexts. This article analyzes the spatialization and alteration processes on the indigenous population of the Toba ethnic group (qom) from the construction of social housing in the Toba neighborhood in the city of Resistencia (province of Chaco, Argentina). The objective of the work questions the ideological modalities from which the de-proletarianized indigenous population in mills and colonial cotton industries progressively arrive as a control object parallel to the modernization processes of the city of Resistencia and the aestheticizing assessment of the political-cultural hegemony of a new province. The core argument states that, during the sixties and seventies, the Toba neighborhood was scene of integrationist subordination in a city that was embellished from the European cultural heritage. To achieve this purpose, documentary and journalistic sources, interviews and images are used methodologically. As a result, it reflects on the subaltern notions of well-being and the emerging incorporation mechanism of indigenous, such as a productive, political, and urbanized subjectivity.
\end{abstract}

KeYwords: Melting pot, indigenous people, integrationism, urban modernization, work, housing 


\section{Introducción}

La provincia de Chaco es una región del noroeste argentino caracterizada como zona de frontera asociada a la configuración del Estado-nación. En 1951, y en el contexto de la primera presidencia de Juan Domingo Perón, Chaco adquirió autonomía como Provincia finalizando la organización de Territorio Nacional desde la denominada "campaña al desierto verde". Desde entonces, la región transitó los procesos de modernización administrativa y cultural que tuvieron auge en las décadas siguientes. También en este periodo se profundizaron los procesos de desplazamiento de grupos indígenas proletarizados hacia contextos urbanos. Estas migraciones poblacionales se solapan con dos acontecimientos en la provincia de Chaco: uno de tipo económico basado en la transformación del modelo productivo asociado al algodón que incorporaba principalmente a mano de obra aborigen; y, otro de tipo estatal, dado un contexto de institucionalización de la autonomía provincial que se articulaba a diferentes actores, proyectos políticos y horizontes de inclusión/exclusión social y cultural.

Por ello, los años sesenta y setenta condensan algunas transformaciones en la estructuración social condicionadas por los efectos de la crisis del modelo de producción algodonero. En conjunción con esa retracción productiva, se abre un periodo de reconstrucción de la hegemonía cultural urbana basada en la institucionalización del embellecimiento urbanístico de Resistencia como ciudad capital, la elitización de los círculos culturales y la legitimación de ideas ancladas en la jerarquía del componente poblacional de origen europeo. Es en este marco que el Barrio Toba, localizado en la zona norte de la ciudad de Resistencia, se instituyó en el imaginario urbano como un lugar marginalizado que se originó como asentamiento espontáneo de familias indígenas migrantes. Del mismo modo, el espacio que progresivamente fue formalizado como "barrio", fue identificado por los sectores medios a partir de la presencia de una alteridad radical respecto a la matriz "blanca" desde la cual los grupos descendientes de inmigrantes europeos construyeron sus pertenencias culturales desde la fundación de la ciudad de Resistencia.

La construcción de las primeras viviendas sociales para poblaciones indígenas en el Barrio Toba nos conduce a problematizar algunas dimensiones sobre las relaciones capitalistas y el lugar de la alteridad indígena como subjetividad productiva. Aquí focalizamos los procesos de espacialización en torno a las viviendas sociales que fueron planificadas entre la Cruz Roja, el municipio de la ciudad y el gobierno provincial. Nuestra hipótesis es que la política indigenista chaqueña, que se encontraba asociada a organismos sanitaristas, condujo tanto a generar mínimas condiciones de bienestar subalterno basada en dos ejes: por una parte, en sustitución de ranchos y tolderías de los asentamientos espontáneos por viviendas de materiales industriales y, por otra, en disposición de mediaciones institucionales para la consecución por parte de las familias indígenas ahora urbanizadas de nuevas fuentes laborales. 
En este sentido, el artículo indaga en las construcciones ideológicas de territorialización y subjetivación de la alteridad indígena en contexto de modernización en la ciudad de Resistencia que, de manera contradictoria, implicó tanto la construcción de viviendas sociales en asentamientos periurbanos como así también nuevas formas de incorporación laboral. Para ello focalizamos en el Barrio Toba a finales de la década de los sesenta comprendiéndolo como escenario de confluencia y constelación de actuaciones institucionales heterogéneas. Para alcanzar este propósito metodológicamente utilizamos fuentes documentales, fuentes periodísticas, entrevistas e imágenes de archivo.

La estructura argumentativa del artículo está organizado en cuatro apartados: en el primero, describimos algunas características de la transformación de Chaco en estructura provincial autónoma y el derrotero de los grupos indígenas como trabajadores en este proceso; en el segundo, focalizamos en las políticas urbanas que promovían la modernización, estetización y embellecimiento en la ciudad de Resistencia en los años sesenta y setenta; en el tercero, indagamos en la emergencia del Barrio Toba en relación a la operatoria de un conjunto de políticas integracionistas y agencias institucionales diversas hacia el indígena; y, por último, describimos los sentidos por los cuales la tutela de Cruz Roja generó modalidades subalternas de bienestar barrial, preocupación por la higiene doméstica desde un modelo hegemónico de vivienda unifamiliar y nuevas formas de incorporación. El objetivo del estudio se inserta en una línea de investigación que indaga desde una lectura materialista en las construcciones ideológicas sobre políticas habitacionales y pueblos indígenas en la provincia de Chaco a partir de articular procesos de larga duración y transformaciones recientes.

\section{Dinámicas estatales y proletarización indígena}

En el norte argentino, en general, la forma dominante de incorporación de la alteridad indígena a la nueva idea de nación fue históricamente mediante el trabajo y la explotación económica más que el exterminio. Desde fines del siglo XIX a comienzos del XX, el periodo de constitución del Estado nacional en Argentina condujo a dos efectos sobre los pueblos indígenas que sintetizan los procesos de dominación hacia el grupo social en particular. En primer lugar, la violencia estatal actuó materialmente sobre las relaciones sociales y condiciones de existencia de los pueblos indígenas: afectó a las familias y su identificación indígena, desarticuló el parentesco y limitó los medios económicos de subsistencia basados. En segundo lugar, se configuró un imaginario social que justificó esa violencia estatal reproduciendo la subordinación social y cultural del grupo étnico respecto a otros. Ambos efectos estuvieron siempre condicionados por las formaciones provinciales de alteridad (Briones, 2005) que implicaron instancias de articulación localizada y específica respecto al "ser nacional". 
Luego del avance militar, la colonización en las territorialidades de La PampaPatagonia y el Chaco occidental como Territorios Nacionales sirvieron para acoger a las poblaciones inmigrantes de origen europeo y sus proyectos de producción económica. Puntualmente mediante la denominada "campaña al desierto verde" - por el contexto de monte-, la conquista en la región chaqueńa se caracterizó por la conversión de mano de obra indígena en trabajadores asalariados o semi-proletarizados (Ińigo Carrera, 2010). El origen heterogéneo de la población indígena, al convivir en los ingenios o colonias algodoneras bajo condiciones similares de explotación, desarrolló una identidad común que antes no existía (Gordillo, 2009). En el proceso de asalarización, siendo parte de la masa laboral no-calificada, la categoría "aborígenes" era una marcación de clase más que de etnia. Al ser producida en el marco de la experiencia laboral, la denominación "aborígenes" adquirió un marcado componente económico que, al mismo tiempo, condicionó procesos de sedentarización limitando las prácticas de "marisca" (como técnica de caza, pesca o recolección, tal como es el caso de las prácticas económicas de la etnia toba) y el aprovechamiento de los recursos de la naturaleza. En efecto, uno de los aspectos que motivó la migración al Gran Resistencia fue el cierre del Ingenio Las Palmas donde la población toba y criolla constituían la masa principal de semi-proletariado. Justamente por su residencia en ámbitos rurales, debían abastecerse del monte y la naturaleza durante la época en que no trabajaban en relaciones asalariadas. Esta subsistencia como "mariscadores" era lo que garantizaba su existencia como fuerza de trabajo disponible para los ingenios.

Si bien para mediados del siglo XX se encontraban mal administradas y en 1943 se registraron huelgas de hambre por parte sus trabajadores (Mathias, 2013), la "reducciones” eran figuras estatales que aún concentraban a los grupos de trabajadores indígenas. Buscaban instruirlos en valores ligados a la laboriosidad y técnicas agrícolas respecto a la producción de algodón y el obraje. No obstante, en 1943 se creó la Comisión Honoraria de Reducciones de Indios como órgano dependiente de la Secretaría de Trabajo y Previsión, y en 1946, pasa a llamarse Dirección de Protección del Aborigen. Por lo que formalmente durante el primer peronismo, este último organismo vigilará en áreas rurales los arreglos para que los ingenios contraten a trabajadores indígenas, "sin mejorar el estado miserable de tales trabajos" (Mathias, 2013, p. 33).

A nivel nacional, esta línea de indagación arriba al inabarcable vínculo entre el peronismo y los pueblos indígenas en Argentina. Como parte de una clase trabajadora mayoritariamente adherida al peronismo, la experiencia indígena contó con amplias concesiones ligadas a los procesos de ciudadanización de un grupo históricamente postergado. Pues, el advenimiento de Perón en el escenario nacional renovó un conjunto heterogéneo de imaginarios racistas sobre las masas sociales que seguían al líder y al movimiento (Grimson, 2016). Como expresa Mathias, "el discurso peronista implica que los aborígenes debían pasar a formar parte de las masas trabajadoras, sin hacer distinción de sus problemas particulares" (Mathias, 2013, p. 27). 
Concretamente en Chaco, en 1951 sus habitantes obtuvieron el derecho de sufragio, los indígenas usaron "libretas de enrolamiento" para votar cuando se instituye la provincia, legitimando como gobernador a Felipe Gallardo ${ }^{1}$. Y, luego del golpe de Estado, es en el año 1956 que la provincia crea la Dirección Provincial del Aborigen a partir de desintegrar la estructura proteccionista nacional precedente. Como expresó Graciela Guarino (2010):

Los comienzos administrativos de la Provincia del Chaco insumieron todos los esfuerzos de las autoridades, por lo que a nivel local la atención de la cuestión indígena pasó más por lo institucional que por resultados mediatos. El gobernador Felipe Gallardo creó en el año 1954 la Dirección Provincial de Acción Agraria y Colonización para la readaptación del indígena, y sólo un año después la Revolución Libertadora interrumpía las políticas impulsadas. Como una de sus primeras medidas suprimió la Dirección de Protección del Aborigen y transfirió sus bienes a las provincias donde el organismo funcionaba, entre ellas el Chaco (decreto-ley No 12.969/56). (Guarino, 2010, pp. 59-60)

No obstante, como en otras regiones indígenas del norte argentino, en Chaco las adscripciones religiosas ligadas a identidades cristianas proliferaron durante la prevalencia de las simbologías y retóricas populistas. Para algunos autores (Salamanca y Tola, 2008), estas identificaciones evangélicas reforzaron los sentidos de pertenencia asociados a lo político-partidario. Durante el peronismo surgió nueva generación de caciques cuya capacidad, combinando prácticas evangélicas y políticas, se sostenía en la negociación con los representantes del Estado nacional (Mathias, 2013).

Es en gran medida el proyecto político del peronismo el que sedimenta en la cultura popular argentina el horizonte deseable y positivo del "bienestar". Como sostienen Papalini y Echavarría (2016):

Es el caso de la palabra "bienestar", cuyo significado está muy habitualmente asociado a una forma particular del Estado. A partir de esta relación, "bienestar" adquiere connotaciones político-económicas al tiempo que, dialécticamente, la imagen del Estado se configura como la del que provee al conjunto de la sociedad, el gran sostén de todos. Dimensiones objetivas y subjetivas se anudan en este concepto. (p. 36)

1 Según Guarino (2010), el contexto de la provincialización del Chaco marcó diferencias respecto al paternalismo de la política indigenista nacional. En concreto, la autora focaliza en los objetivos del Segundo Plan Quinquenal del gobierno peronista como una política para reformular el problema de los indios en base a los datos cuantitativos (registro de nacimientos y enrolamiento de adultos indígenas indocumentados, etc.) y un amplio proceso de reivindicación de sus derechos sociales. No obstante, es necesario aclarar que el derecho a la vivienda por parte de los pueblos indígenas tuvo consideración recién en 1987 a partir de la sanción de la Ley del Aborigen Chaqueño, ya en contexto de la recuperación democrática. 
En este sentido, es necesario puntualizar en las contradictorias expresiones con que la mentada "democratización del bienestar" (Torre y Pastoriza, 2002) suscitó marcadas conflictividades y renovadas lógicas de violencia (Mapelman, 2015) cuando se observan las dinámicas territoriales de las poblaciones indígenas. En el intrincado anudamiento de dimensiones objetivas y subjetivas del bienestar de una determinada época, la construcción del problema habitacional para indígenas urbanizados fue parte de esas opacidades. Al mismo tiempo, instituyó distancias y fronteras tanto en términos de etnicidad como de clase social que nos proponemos abordar.

\section{La modernización provincial y el embellecimiento urbano de Resistencia}

Con el paso del periodo territoriano al de provincianía ${ }^{2}$, en Chaco se activan imaginarios estético-políticos proyectados desde la elite cultural que residía en la ciudad de Resistencia, su capital, hacia toda la provincia. Las primeras simbolizaciones de lo "chaqueño" como complejo identitario normativizado en dos constituciones (1951 y 1957) estuvieron basadas en la resignificación de los relatos fundacionales, los cuales muestran continuidades y rupturas respecto al pasado territoriano. Pero el periodo de provincialización no solo concedió autonomía política y administrativa, sino que también condujo a procesos de modernización de la hegemonía cultural. En estas dinámicas, la producción de categorías y criterios de identificación/clasificación presenta dos características: en primer lugar, es a partir de la década del sesenta que se articularon con mayor fuerza los distintos discursos totalizadores de pertenencia provincial; $y$, en segundo lugar, los supuestos de las elites culturales y gubernamentales sentaron las bases a partir de lo cual se organizó una identidad del "nosotros" chaqueño. El modelo de autonomía provincial consolidó la hegemonía cultural del "Chaco gringo" en su referencia a la moralidad vinculada al esfuerzo del trabajo y a las matrices culturales de inmigrantes europeos. Estas representaciones consolidaron la incorporación de sectores subalternos indígenas y criollos como proletarios y sectores subordinados.

Ya en los años cuarenta, las discursividades urbanas dominantes van a contribuir al embellecimiento de Resistencia como valor arquitectónico e ideología del progreso (Sudar Klappenbach, 2011). Desde esta década, se fueron gestando en la ciudad de Resistencia espacios culturales conformados por sectores medios ligados principalmente

2 En el desarrollo historiográfico del Chaco, posterior a la construcción del "desierto verde" (1884-1917) en el circuito económico nacional, se destacan dos periodos: la etapa territoriana hasta 1951 (referida al Territorio Nacional de Chaco) y la etapa provinciana desde 1951 hasta el presente (referida a la provincia "Juan Domingo Perón" hasta 1955 y luego del golpe de Estado pasa a denominarse "Provincia de Chaco"). A lo largo del siglo XX, la historiografía y la producción cultural se concentran en torno al debate sobre el origen de la ciudad de Resistencia y luego sobre la identidad provincial en un contexto de otorgamiento de tierras a colonos de origen europeo quitadas a indígenas. 
a la pintura y la escultura. Para algunos autores, El Fogón de los Arrieros emergió con fuerza en el contexto de la provincialización de Chaco, logró rápidamente reconocimiento a nivel nacional y se constituyó en una propuesta "cosmopolita" tendiente a articular una identidad singular en relación con una idea de ciudad (Cantero, 2012). El lugar que ocupó este círculo en la capital provincial propició un efecto discursivo que permeó en gran parte las políticas culturales tanto para la provincia de Chaco como para la ciudad de Resistencia. En este ámbito, lo artístico pasaba más por generar componentes folklóricos y estéticos identificados como lo aborigen, lo criollo o lo inmigrante para esquematizar el mapa identitario.

En 1961, El Fogón de los Arrieros puso en marcha el denominado "plan de embellecimiento" de Resistencia que tenía como propósito estetizante la limpieza de las banquinas en la cuadra donde se localizaba el centro cultural. Esta iniciativa suponía la participación por parte de los vecinos a través de la colocación de plantas y el emplazamiento de esculturas en el espacio público. La propuesta proponía también la realización de murales al aire libre. Esta iniciativa fue difundida con el objeto de que otros grupos de vecinos imitaran la idea de El Fogón. De hecho, algunos historiadores han afirmado que "gran cantidad de vecinos se lanzaron decididamente a participar del movimiento, hermoseando los jardines de las veredas" (Gutiérrez Viñuales y Giordano, 1992, p. 166). La colocación de estatuas fue interpretada como la fantasía artística tendiente a "hermosear" la ciudad caracterizada por sus veredas amplias y cuadrícula urbanística $^{3}$. Para la prensa, la iniciativa de El Fogón de multiplicar los pequeños jardines floridos, en las calles y los rincones de Resistencia, convirtió a la ciudad en una especie de museo al aire libre. En un primer momento, la acción de "embellecer a la ciudad" fue interpretada por la Municipalidad de Resistencia como una amenaza a sus competencias políticas. Con el correr de las décadas, se fue produciendo la paulatina institucionalización de la ciudad como "Capital de las Esculturas" dada la práctica de emplazar piezas escultóricas de diferentes autores en las avenidas, plazas y veredas. Desde entonces, el municipio de Resistencia deviene como un promotor de la práctica escultórica hasta nuestros días.

En este contexto, se produce la activación del discurso del "crisol de razas" que operó como estrategia para organizar y representar las diferencias culturales de la provincia. Como expresa Mariana Giordano, “a partir de la década del 1960 la pluralidad

3 La fundación de la ciudad de Resistencia en 1878, denominación popularmente significada por "la resistencia frente al indio" (Cantero, 2012), fue instituida al interior de la racionalidad de la urbanística liberal decimonónica inspirada en modelos higienistas europeos y americanos. Apuntalando la funcionalidad a una realidad entendida desde el punto de vista económico y de la producción, las diferentes mensuras a la Colonia de Resistencia fueron introducidas por Seelstrang y Foster definiendo el trazado general de la planta urbana e imponiendo una "parrilla territorial” (Sudar Klappenbach, 2004). De acuerdo al modelo hispano de cuadrícula, se dispuso totalmente de manera regular y simétrica a las manzanas y anillos de circunvalación, e incluso, a la diagramación de la plaza central y plazas periféricas. 
comenzó a visualizarse como un valor en la conformación social y étnica argentina” (Giordano, 2012, p. 302). Los imaginarios culturales resistencianos aludían a la figura del crisol como una referencia a la fusión de tres trazos idiosincráticos a partir del inmigrante friuliano, el hachero y el cosechero criollos; y el peón indígena. Este dispositivo ideológico fue proyectado a toda la provincianía, pero en la práctica los componentes identitarios nunca tuvieron otra relación más que la del distanciamiento cultural. Y esto se inscribió tanto en el discurso cultural como en el discurso político ligado a funcionarios y autoridades estatales no indígenas.

Estas dinámicas culturales afectaron tanto el mundo simbólico chaqueño como el mundo material y urbanístico de la ciudad de Resistencia a partir de la apropiación estética del espacio urbano. De allí que, como veremos, tanto los proyectos de "embellecimiento urbano" como el discurso sobre cierta forma de diversidad cultural operan como dispositivos ideológicos y formas de renovar distancias sociales en la ciudad. El Barrio Toba, como veremos más adelante, es resultado de estas distancias sociales urdidas en las representaciones idealizadas o esencializadas del componente indígena en diferentes artistas chaqueños (Giordano, 2008).

\section{El Barrio Toba como asentamiento de trabajadores}

El Barrio Toba surgió en el contexto de la primera y segunda presidencia de Juan Domingo Perón (1946-1955) y en el marco de reclamos por la propiedad de la tierra desde los sectores indígenas desplazados de la región central de la provincia. El impulso estatal de la colonización se había estimulado haciendo que, con el aumento de privatizaciones de las tierras públicas, disminuya el arraigo en el interior provincial. Al mismo tiempo, la profundización de la crisis agrícola-forestal que configuraba el modelo productivo provincial impactó en la estructura demográfica y en emigración rural hacia las ciudades más pobladas.

Desde este periodo, la ciudad de Resistencia apareció como polo receptor originando el poblamiento de tierras fiscales sobre lo que luego sería el Barrio Toba (Guarino, 2006). Por entonces, Resistencia se proyectaba desde el desarrollo económico debido a su nueva jerarquía administrativa y funcional, lo cual la ubicó como un centro de atracción para esta migración rural. Por su localización, era el sitio es la puerta de ingreso del inmigrante proveniente del interior de la provincia. En efecto, la traza original del barrio primeramente conocido como "Las tolderías" responde a un asentamiento espontáneo, al costado de las vías del tren, y sus procesos de poblamientos se insertan en lógicas migratorias y lazos parentales. En los trabajos de asesoría estatal de 1969, la antropóloga Esther Hermitte y su equipo técnico narraban así la conformación del barrio en los años cincuenta durante el contexto del primer peronismo: 
A un grupo de aborígenes que habitaban el lote 170 se les prometen tierras en la zona de Colonia Aborigen Chaco, asegurándoseles que la señora Perón los esperaba ahí para otorgárselas. Abandonan sus tierras y se dirigen a pié hasta la Colonia Aborigen Chaco, encontrando al llegar que no existía tal posibilidad. De regreso a su asentamiento anterior lo encuentran cercado y ocupado por blancos, proceso que se ha repetido frecuentemente en la provincia por el avance de la población criolla y europea que se radica en ella. Migran entonces los indígenas a lo que hoy es el barrio y establecen sus "toldos" en zonas bajas y anegadizas a ambos costados de la vía. La migración posterior se realiza en forma individual o de pequeños grupos, frecuentemente vinculados por lazos de parentesco con moradores anteriores. (Hermitte y equipo, 1995, p. 163)

A fines de los años sesenta, el Estado como lugar de enunciación de la política indigenista se valió de estrategias para integrar/diferenciar e incluir/excluir a las alteridades étnicas y de clase. El desafío de la nueva provincianía y el Dirección del Aborigen Chaqueño como responsable de política indigenista buscaron conocer qué características tenía esa población indígena hasta entonces desconocida y cuál era su situación socioeconómica. Como el Estado no contaba con técnicos o profesionales para esa tarea y siendo que se requería viajar hasta localidades alejadas en gran parte de la geografía provincial, el vínculo entre el gobierno provincial y Consejo Federal de Inversiones (CFI) subsanó esta deficiencia estatal. En efecto, la Dirección Provincial del Aborigen demandó al CFI la realización de un informe sobre la situación de poblaciones indígenas y su nivel de vida, que a su vez contrató a los profesionales y antropólogos del Instituto Di Tella en Buenos Aires (Hermitte y equipo, 1995). Entre 1969 y 1970, la reconocida antropóloga Esther Hermitte dirigió el proyecto interdisciplinario en cuatro localidades chaqueñas, siendo una de ellas el Barrio Toba de la ciudad de Resistencia. Como hemos reflexionado en otro texto (Quevedo, 2020), esta experiencia de consultoría no sólo es una interesante fuente historiográfica, sino que permite problematizar a los propios actores del antropológico dentro de la hegemonía desarrollista durante la dictadura de Onganía en Argentina y en la singularidad de la provincia de Chaco a partir de la proscripción del peronismo.

Durante estas décadas, la presencia indígena se había expandido a las grandes ciudades del país y los censos indígenas — principal característica de la política indigenista de la época - tendieron a invisibilizar estas dinámicas porque sostenían que el indígena auténtico estaba en áreas rurales (Gordillo y Hirsch, 2010). En efecto, en Resistencia, la falta de "integración" de los sectores indígenas estaba representada en el sentido común por los procesos de urbanización suscitados en la ciudad capital. El indígena y su marginalidad no eran una de las escenas deseables para las clases medias resistencianas en plena modernización urbanística. El concepto de "integración” en el debate político chaqueńo quedaba reducido a la frase con la cual el Ministerio del Gobierno 
provincial saludó al equipo de investigadores que se dirigía a hacer el trabajo de campo: "Señores, no quiero un indio más en Resistencia"” (Ińigo Carrera e Isla en Hermitte y equipo, 1995, p. 24). Es decir, la idea de política integracionista en el periodo se asociaba a la incorporación como un semi-proletariado en contexto rural y procuraba, en algún punto, restituir los grupos indígenas a ese marco.

No obstante, cuando estos antropólogos metropolitanos llegan al Barrio Toba se encuentran con un conjunto de agentes en el territorio que tutelaban la permanencia de población toba (aunque el barrio tenía residentes criollos). Nos referimos a la presencia de la Cruz Roja que desde 1961 mantenía intervenciones cotidianas en el asentamiento. En este periodo, los imaginarios integracionistas de raigambre desarrollista se cristalizaban en los recurrentes intentos de desalojar a la población indígena de la ciudad de Resistencia. El informe de Hermitte y equipo (1995) fue enfático en reconocer las acciones estratégicas que por esos días llevaba adelante la Cruz Roja en la barriada. La Municipalidad o la Dirección Provincial del Aborigen no tenían presencia en el barrio, como sí esta filial bajo la Comisión de Señoras y el aval de la Guarnición de Monte. Es decir, como Chaco era considerado zona de frontera, la presencia de Cruz Roja se comprendía como institución ligada a la órbita del Ejército y al cuerpo de la Guardia Nacional. Desde sus orígenes, el Barrio Toba de ciudad de Resistencia es comúnmente señalado como un entorno étnico y de clase social de una ciudad moderna fundada al calor de los proyectos de colonización e inmigración europea pero donde la Cruz Roja ocupó un lugar central en la construcción de las redes de poder entre vecinos, líderes políticos y agentes del gobierno provincial.

\section{Bienestar subalterno y viviendas para la alteridad}

La construcción dominante del "problema indígena” y la caracterización del hábitat urbano como nuevo escenario social producto de desplazamientos en este periodo adquiere disímiles abordajes en la bibliografía académica. Estos procesos, que a menudo fueron interpretados desde nociones antropológicas como las de cambio cultural, no siempre focalizaron en aspectos relacionales del entorno urbano y en actores institucionales involucrados en estas transformaciones en los contextos receptivos. Más bien, los trabajos abordaron las estrategias adaptativas desde las prácticas culturales, lógicas de supervivencia y las nuevas redes de sociabilidad indígenas desplegadas en los propios territorios urbanizados (Bartolomé, 1984; Guarino, 2006).

Es desde otro punto de vista que postulamos nuestra hipótesis de trabajo sosteniendo que, en esta época, la política indigenista chaqueña, mediante su articulación con organismos sanitaristas, generó condiciones de bienestar subalterno como lógica de dominación eficaz desde dos niveles. Por una parte, los procesos de sustitución de 
ranchos y tolderías por viviendas de materiales industriales significaron una entrada subordinada a la modernización y al embellecimiento urbano pregonados en los valores hegemónicos; y, por otra parte, de las nuevas lógicas de incorporación laboral e informal en el contexto urbano posibilitaron la reproducción de condiciones materiales de existencia y, en el mismo sentido, la actualización y el reacomodamiento de lo indígena como subjetividad productiva tanto como subjetividad política.

En el imaginario simbólico del peronismo, el acceso a la vivienda propia es un signo tanto del proceso de ampliación de la ciudadanía social por parte de los trabajadores como del acceso a mayores niveles de bienestar y confort (Aboy, 2005). En ese horizonte, las narrativas sobre el origen histórico del Barrio Toba a menudo focalizan en la construcción de las viviendas consolidadas y remite a la presencia de la Cruz Roja como organismo de ayuda humanitaria en el lugar. En ese marco, la figura de Inés García de Marqués es sacralizada en el imaginario toba como "una mujer muy exigente" (entrevista a Graciela, Barrio Toba, 2016) que "siempre los escuchaba cantar y un día les preguntó si se animaban a cantar afuera" (entrevista a miembro del Coro Toba, 2016). Como advertimos en la imagen 1 , a poco tiempo de arribar al barrio la impulsora de la Cruz Roja había concretado las primeras presentaciones de la formación coral (es decir, una práctica no indígena) a partir del canto grupal en lengua qom.

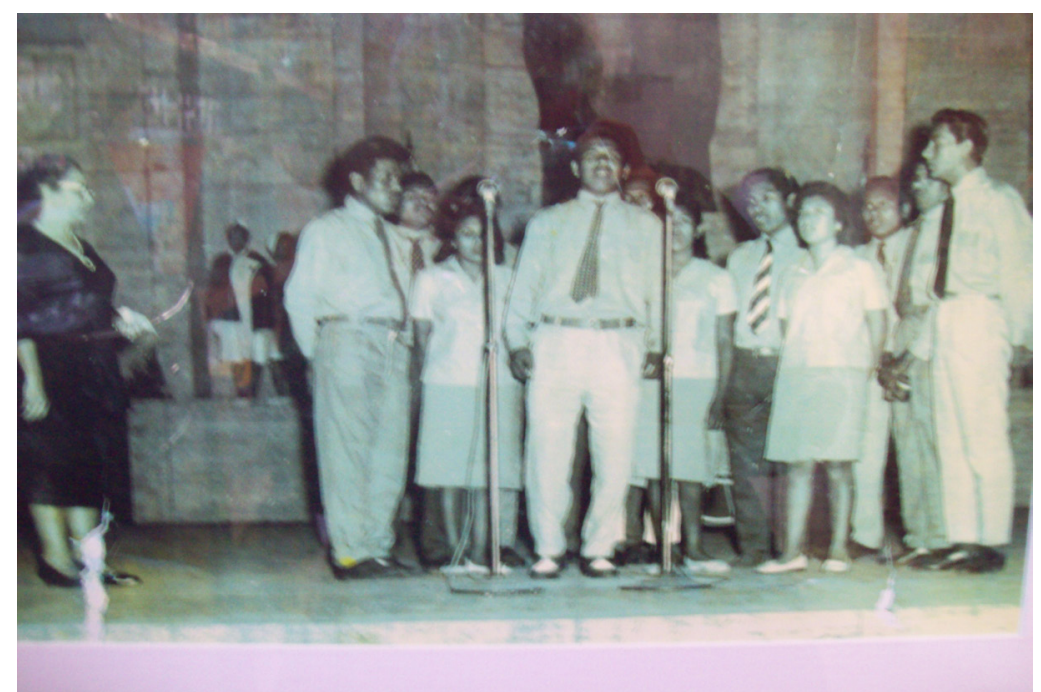

ImAGen 1: De izquierda a derecha, Inés García de Marqués e integrantes del Coro Toba (ciudad de Rosario,1962). Fuente: Museo del Coro Toba.

Según el censo barrial que realizó la Cruz Roja en 1968, el Barrio Toba tenía poco más de 1200 habitantes con un 60\% de población toba. La construcción progresiva de unidades habitacionales con materiales industriales es interpretada como resultante de 
un periodo donde se "comienzan a visualizar esperanzas sobre la tenencia definitiva de la tierra, en función de las negociaciones entre el municipio y el ferrocarril" (Hermitte y equipo, 1995, p. 157). En esta etapa, los trabajadores indígenas, despojados tanto de sus territorios de origen como de sus lugares de trabajo en el modelo productivo, encontraban en el Barrio Toba una posibilidad de reproducir o negociar sus condiciones materiales de existencia.

En el presente, la Cruz Roja es recordada como aquella institución mediadora que impidió los intentos de relocalización y nuevas desterritorializaciones de los sectores indígenas en la ciudad. No obstante, García de Marqués personifica la voluntad de la Cruz Roja de sostener el Barrio Toba dado que ella "medió para que los habitantes permanezcan en ese emplazamiento" (Revista Chaqueña, 2015). En este sentido, en el imaginario local es "la gestión de la Cruz Roja" la que instituye al barrio y no la organización de las familias indígenas, sus lazos sociales precedentes o las instituciones del Estado.

La edificación de las viviendas sociales en el Barrio Toba tiene dos etapas a partir de la disponibilidad del suelo urbano en lo que fueron las vías del ex ferrocarril General Belgrano: en cada etapa se construyen 110 unidades habitacionales en el Pasaje Cruz Roja y en el Pasaje Wainolek. Popularmente se reconoce que fue la gestión de la Cruz Roja Argentina la que planificó el Barrio Toba, otorgando a las 220 viviendas en lotes individuales unas dimensiones de $6.80 \mathrm{~m}$. x $21.00 \mathrm{~m}$. Esto produjo un barrio lineal que replica la forma del terreno de la ex vía y crea manzanas de más de $100 \mathrm{~m}$. de longitud. La característica más distintiva de las viviendas es que poseen un techo abovedado que, como tipología, también fue construido en otros barrios de ciudad.

Si bien es recordada la presencia de Deolindo Bittel ${ }^{4}$, por entonces gobernador y líder peronista, caminando por el barrio y observando el levantamiento de las viviendas, no existe una institución con mayor presencia que la Cruz Roja aun en la planificación del barrio. En el proceso de construcción y otorgamiento de viviendas sociales a la población toba, la Cruz Roja adviene como un actor en dos direcciones: por un lado, hacia afuera de la vivienda interviene en el ordenamiento urbanístico y la localización de las familias y, por otro lado, hacia adentro de la vivienda es la institución encargada de moralizar las condiciones de habitabilidad desde parámetros sanitaristas externos a la comunidad indígena. En concreto, la Cruz Roja recomendó a la municipalidad de Resistencia que el otorgamiento de tierras tenga por objetivo separar las familias extensas a partir del otorgamiento de los lotes pequeños que perduran hasta el presente. En unos de los pasajes del informe de Hermitte se enuncia:

4 Por el peronismo, Bittel ocupó la Vicegobernación del Chaco (1953-1955) y es elegido dos veces Gobernador (1963-1966; 1973-1976), aunque una elección se anula y las dos oportunidades restantes no concluyó su mandato por golpes de estado. También se desempeńó como Intendente de la ciudad de Resistencia, candidato a vicepresidente de la Nación y Senador. 
No se puede trazar líneas muy claras que distingan la vivienda indígena de la de criollos. Debemos recordar que en la década transcurrida desde que se iniciara la acción de la Cruz Roja se ha modificado su aspecto. Las diferencias cruzan las líneas étnicas, y hay viviendas muy precarias tanto entre indígenas como en criollos. Lo mismo sucede con las de mejor material y construcción. Un rasgo netamente aborigen que se da en algunos casos es el agrupamiento de unidades en un solar común, explicable por la herencia cultural Toba que da prioridad a los derechos y deberes de la familia extensa. De estas hay pocas porque hace años la Municipalidad, a pedido de la Cruz Roja, subdividió el espacio del barrio en lotes pequeños que amojonó, dando cada uno a una familia. (Hermitte y equipo, 1995, p. 194)

De este modo, los mecanismos políticos de localización, otorgamiento y distribución de las parcelas de tierras se articularon a los presupuestos etnocéntricos basados en una idea de familia nuclear. A su vez, al interior de la vivienda, la Cruz Roja aparecía como un artífice de la promoción de prácticas "adecuadas" en materia de higiene, salud y alimentación. Por ejemplo, "los beneficiados son aquellos demuestran en su actitud y en sus casas el aseo y labor que se les ha inculcado" (Hermitte y equipo, 1995, p. 185). Esta condición era solicitada en caso de tener mercaderías o donaciones para distribuir entre la población del barrio, lo que también generaba asperezas por el favoritismo respecto a indígenas ante que criollos.

A casi una década de su iniciación, la Cruz Roja continua su obra asistencial. La acción de esa filial abarca aspectos educativos, culturales, sanitarios, religiosos, recreativos, organizativos a nivel de comunidad y más allá de ésta, trata de ubicar a indígenas en el mercado de trabajo de la ciudad de Resistencia. (Hermitte y equipo, 1995, p. 173)

Además, el informe realizado por Hermitte y equipo (1995) señala las acciones desplegadas por el Club de Madres que funcionaba bajo los lineamientos de Cruz Roja. Este club tenía objetivos puntuales que representan cómo se naturalizaban ciertos valores dominantes en relación al espacio doméstico y al espacio público en el barrio. En primer lugar, la institución proveía educación primaria para los niños que inmortalizó uno de los roles de la Cruz Roja en el barrio como la impulsora de la creación de la escuela en 1962. De allí que consideramos que, más que la incidencia de sus criterios integracionistas y sanitaristas basados en la impugnación de la familia extensa y otros tipos de moralizaciones (Quevedo, 2017), el organismo es recordado como un articulador social. Como vemos en la imagen 2 , una de las tareas más gravitantes fue la promoción de distintas arenas culturales fundamentalmente a partir de la creación de la escuela primaria que mantuvo bajo su órbita hasta el año 2011. 


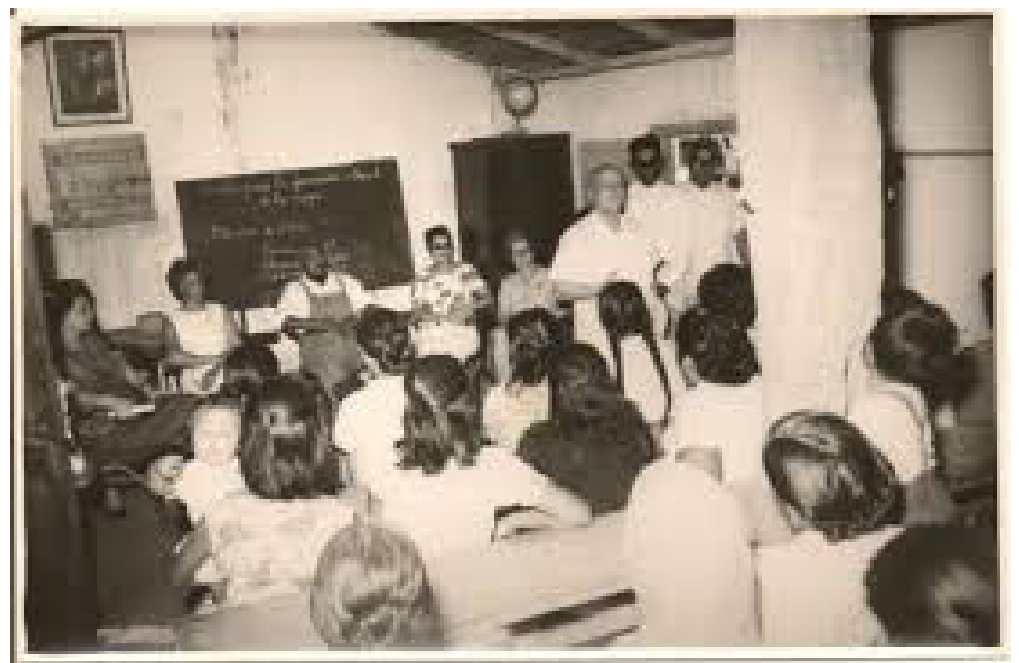

IMAgEN 2: La escuela del Barrio Toba en los ańos sesenta. Fuente: diario Norte.

En segundo lugar, el Club de Madres administraba para las mujeres del barrio educación en base al valor de la higiene y el cuidado del hogar. Principalmente, se impartían instrucciones para la preparación correcta de alimentos, el sostenimiento de la huerta, las prácticas de aseo personal y del hogar, administración del salario, lavado de ropa, asistencia al templo católico, etc. Como podemos advertir en la imagen 3, las actividades consistían en el clásico modelo pedagógico donde la mujer blanca enseñaba a realizar ciertas tareas a mujeres indígenas. Estas actividades hogareñas debían ser imitadas en sus respectivas familias y sobre este punto se impartía una especial vigilancia.

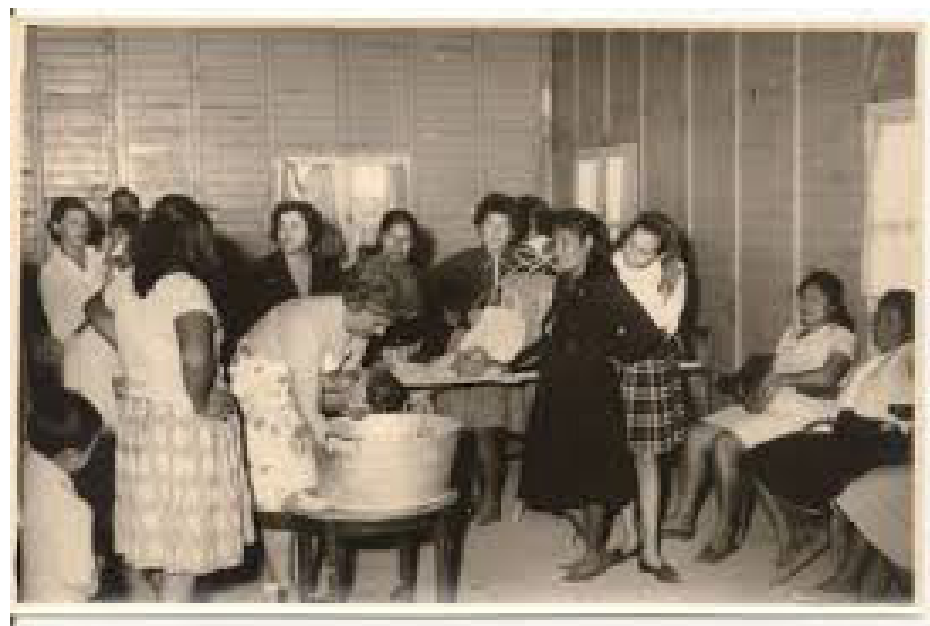

ImAGen 3: Club de Madres en el Barrio Toba. Fuente: diario Norte. 
En tercer lugar, este espacio también tenía como objetivo la enseñanza de prácticas democráticas para los adultos. La Cruz Roja promovió activamente la participación institucional, el involucramiento en el mejoramiento del aspecto del barrio, el cuidado de la única calle del barrio los días de lluvia, la plantación de árboles para sombra, y la generación de conciencia sobre la limpieza de casas y patios. Un aspecto no menor es que se había organizado 9 equipos con unos veinte aborígenes cuya principal tarea era supervisar y promover las acciones antes mencionadas. De la misma forma, es significativa la descripción que realizan los técnicos sobre la idealización de los procesos democratizantes por parte de la Cruz Roja. Pues, los diagnósticos locales celebraban la ausencia de la figura del cacicazgo por comprenderla innecesaria en la dinámica que había adquirido el Barrio Toba y, claro, por constituirse en una expresión atávica.

Quizás unas de las acciones más valoradas era la capacidad de ubicar indígenas en el mercado de trabajo, lo cual coincidía cabalmente con la pretensión integracionista de la época. De hecho, según el censo realizado por la Cruz Roja, un 27\% de la mano de obra aborigen masculina contaba con una ocupación como obrero, empleado municipal o provincial, mucho del cual era resultado de la capacidad de injerencia de la Cruz Roja en algunos espacios de poder de la ciudad. En el presente, es muy frecuente que los ancianos recuerden que, en su juventud, por ejemplo, Inés les había conseguido un empleo como policía, lo que le permitió poder sostener a su familia.

Además, es interesante la gran proporción de artesanos y artesanas indígenas en el barrio (el 36\% de la mano de obra masculina y el 85\% de la femenina) dada la promoción de este tipo de labores "tradicionales" en aquella época. En efecto, se había creado la Cooperativa de Artesanos Alfareros a través de la cual se comercializaban piezas de cerámica en un local del mismo barrio y en un puesto en el aeropuerto. Del mismo modo, también era dominante la realización de las denominadas "changas" (23\% de la población indígena masculina) en distintos trabajos informales y ocasionales. Sólo el $3 \%$ se desempeñaba como peón agrícola en áreas rurales, dato que confirma la retracción productiva ya mencionada.

No obstante, es interesante el seńalamiento que realizan los consultores al confrontar el censo realizado por la Cruz Roja con los datos obtenidos en la experiencia del trabajo de campo, lo que permitía a dimensionar el real alcance de la incorporación aborigen en el mercado de trabajo de la ciudad:

Si bien los datos del último censo de la Cruz Roja muestran que sólo el 7\% de los aborígenes se declaraban desocupados, hay que tener en cuenta la condición de desocupación que se encubre detrás de la categoría "changas". Un 23\% de los aborígenes declara trabajar en changas. Se puede afirmar que no existen límites claros entre ambas categorías e incluso, entre esas dos y el trabajo artesanal. El Censo registra la desocupación en changas y artesanías, pero la conformación obtenida a través del trabajo de 
campo permite asegurar que ambos tipos de ocupaciones se combinan en una gran cantidad de casos. (Hermitte y equipo, 1995, p. 190)

Los objetivos de premisa integracionista de la época que, mediante la órbita de la Cruz Roja, tenían un saldo que en la época podría valorarse como positivo. Solo el 7\% de desocupación parecía una cifra insignificante mirando los primeros años de la década del sesenta y la marcada desigualdad que los propios actores institucionales denunciaban cuando llegaron. De manera que el acceso a la vivienda y la formalización del acceso a la tierra, promovían los alcances de bienestar y la higiene al haberse alejado de la imagen inmoral de las tolderías miserables e improvisadas. Al mismo tiempo, los beneficios de la Cruz Roja sustituían lo que en otra época fue el bienestar relativo y contradictorio alcanzado por la proletarización histórica de los aborígenes. De este modo, el Barrio Toba entraba al esquema de la modernidad urbana reservado para los habitantes de sectores medios y blancos del centro de la ciudad de Resistencia de la mano de los proyectos de civilización de los agentes e instituciones locales.

\section{Conclusión}

En la década del sesenta, los ingenios se mecanizan y adoptan sistemas automatizados profundizando los procesos de expulsión de la población aborigen semi-proletarizada en contextos rurales. Habiéndose radicado en nuevos asentamientos urbanos, esta situación conduce a la necesidad de recomponer lazos en busca de mecanismos alternativos de reproducción socioeconómica. Como escenario de estas dinámicas territoriales, el Barrio Toba ofrecía una amalgama de posibilidades de supervivencia, socialización y subalternización respecto a una ciudad de Resistencia "blanca" y progresivamente estetizada. Por lo que, al relacionar el clima de época y el rol de la elite cultural en las políticas de embellecimiento dominantes en la ciudad de Resistencia con respecto a la emergencia y visibilización del Barrio Toba, advertimos su ingreso de manera diferencial y subordinada a la modernización urbana y provincial.

En este sentido, el artículo reconstruyó la particularidad histórica local de las décadas de los sesenta y setenta donde se produce el encuentro de actores, agencias y mecanismos de control social en torno a los espacios domésticos, la vivienda y el trabajo. $\mathrm{Si}$ bien partimos de considerar que estas agencias se configuraron como dispositivos de espacialización para transformar las experiencias tradicionales de familias y grupos étnicos, consideramos que los trabajadores indígenas han sido protagonistas activos en la negociación de procesos de mestizaje y la constante resignificación de sus prácticas políticas. De tal manera que el reconocimiento del derecho a la vivienda de grupos indígenas no solo es un otorgamiento de reparación o reivindicación cultural del trazo 
idiosincrático más marginal en el discurso del "crisol de razas". También cumplía estratégicamente las funciones de asepsia y control social para modelar a la alteridad o transformarla. Esta experiencia analizada ha reconstituido tanto la subjetividad productiva como la subjetividad política de dos maneras: por una parte, desde los imaginarios subordinados a los discursos estético-político-culturales y las novedosas formas de incorporación social de la diferencia en contexto urbano; y por otra parte, las dimensiones espaciales del Barrio Toba en las que se operaron disputas desde las prácticas cotidianas de los vecinos y las vecinas por resistir significados y maneras de hacer hegemónicos.

La historización de la tutela de la Cruz Roja a la población toba nos resulta una problematización gravitante para comprender el integracionismo estatal y la espacialización de la hegemonía desde espacios domésticos y barriales. En escasas ocasiones, los estudios académicos focalizaron en las prácticas de regulación y disciplinamiento en las maneras de hacer y proceder en los espacios domésticos subalternos. Como expresa Mathias, "para entender la persistencia del peronismo en estas regiones, no sólo deben estudiarse las políticas del gobierno nacional sino también deben analizarse las posibilidades y los límites de la "democratización del bienestar" desde los ojos de los propios aborígenes" (Mathias 2013, p. 44). Así, las relaciones sociales que se cristalizan en torno al derecho a la vivienda para familias tobas contribuyen a evidenciar tanto las lógicas que buscaban "civilizar" sus prácticas, así como también encauzar las estrategias hegemónicas para reproducir moralidades ligadas al trabajo, al bienestar, a la limpieza, a la organización barrial o la reproducción de la familia (nuclear) de los aborígenes.

\section{Referencias}

Aboy, R. (2005). Viviendas para el pueblo. Espacio urbano y sociabilidad en el barrio Los Perales. 1946-1955. Buenos Aires: Fondo de Cultura Económica-Universidad de San Andrés.

Bartolomé, L. (1984). La familia matrifocal en los sectores marginados: Desarrollo y estrategias adaptativas. Runa, XIV, 23-49.

Briones, C. (comps.) Cartografias argentinas: politicas indigenistas y formaciones provinciales de alteridad. Buenos Aires: Antropofagia.

Cantero, E. (2012). Ciudad de Resistencia. Discursos e imaginarios sociales en torno al origen de su nombre (Tesis de la Licenciatura en Sociología). Universidad Nacional de Villa María, Argentina.

Giordano, M. (2008). Discurso e imagen sobre el indígena chaqueño. La Plata: Colecciones al margen.

Giordano, M. (2012). Fotografía, testimonio oral y memoria. (Re)presentaciones de indígenas e inmigrantes del Chaco (Argentina). Memoria Americana 20, 2, 295-320. 
Gordillo, G. (2009). La clientelización de la etnicidad: hegemonía partidaria y subjetividades políticas indígenas. Revista Española de Antropología Americana, 39, 2, 247-262.

Gordillo, G. y Hirsch, S. (Comps.) (2010). Movilizaciones indigenas en la Argentina. Buenos Aires: La crujía.

Grimson, A. (2016). Racialidad, etnicidad y clase en los orígenes del peronismo, Argentina 1945. Working Paper Series, 93, Berlin: desiguALdades.net International Research Network on Interdependent Inequalities in Latin America.

Guarino, G. (2006). Los tobas de la ciudad de Resistencia: el desafío de vivir en los márgenes. Cuaderno Urbano, 5, 35-54.

Guarino, G. (2010). Estrategias identitarias para la resistencia étnica en las organizaciones indígenas Qom del Chaco. Rev Mad., 22, 56-72.

Gutiérrez Viñuales, R. y Giordano, M. (1992). El Fogón de los Arrieros y el plan de embellecimiento de Resistencia durante la década del sesenta. Resistencia: Fundanord.

Iñigo Carrera, N. (2010). Génesis, formación y crisis del capitalismo en el Chaco, 1870-1970. Salta: UNSA.

Mapelman, V. (2015). Octubre Pilagá, memorias y archivos de la masacre de La Bomba. Buenos Aires: Tren en movimiento.

Mathias, Ch. (2013). ¿Peronismo indígena? La construcción de un nuevo sujeto político en el chaco argentino (1943-1955). Revista Estudios del ISHiR, 3, 7, 26-44.

Papalini V. y Echavarría C. (2016) Los significados contrapuestos del bienestar: de la felicidad al wellness. Revista Ensambles, año 3, No 4 y 5, pp. 35-53.

Quevedo, C. (2017). Imaginario integracionista, espacio doméstico y alteridad indígena en la ciudad de Resistencia. Ponencia presentada en el XXI Jornadas Nacionales de Investigadores en Comunicación "La comunicación en la producción del conocimiento, como objeto de políticas públicas y políticas universitarias, en contexto de desinversión”, ciudad de San Juan, 5 al 7 de octubre de 2017. Recuperado el 12 de diciembre de 2020 en http://redcomunicacion.org/imaginario-integracionista-espacio-domestico-y-alteridad-indigena-en-laciudad-de-resistencial

Quevedo, C. (2020). Saberes expertos e indígenas urbanos en los años sesenta y setenta (provincia de Chaco, Argentina). Cardinalis, en prensa.

Rosas, S. (2016). Violencia e invisibilidad indígena: la cuestión de los pueblos originarios durante el primer peronismo. Anuario del Instituto de Historia Argentina, 16 (1), e013.

Salamanca, C. y Tola, F. (2008). Formas contemporáneas de la acción política toba a partir del análisis de las estrategias relacionales qom y de la capacidad de acción. En J. Braunstein y N. Meichtry (Eds.), Liderazgo, representatividad y control social en el Gran Chaco (pp. 149158). Corrientes: UNNE.

Sudar Klappenbach, L. (2004). La colonia Resistencia como modelo de fundación republicana. Procedimientos fundacionales y características urbanas. Cuaderno Urbano, 4, 117-143. 
Sudar Klappenbach, L. (2011). Puntos de diálogo para pensar la relación entre fotografía, patrimonio e identidad urbana. En M. Giordano y A. Reyero, A. Identidades en foco. Fotografía e investigación social (pp. 231-253) Resistencia: IIGHI-UNNE.

Torre, J. C. y Pastoriza, E. (2002). La democratización del bienestar. En: J. C. Torre (dir.), Nueva Historia Argentina, Tomo VIII, Los años peronistas (1943-1955). Buenos Aires: Sudamericana.

\section{Fuentes consultadas}

Hermitte, Esther y equipo (1995). Estudio sobre la situación de los aborígenes en la provincia del Chaco y politicas para su integración a la sociedad nacional. Posadas: Editorial Universitaria de Misiones. Vol. III.

Entrevista realizada a Graciela, Barrio Toba, Resistencia, julio de 2016.

Entrevista realizada a miembro del Coro Toba, Resistencia, julio de 2016.

Revista Chaqueña (15 de agosto de 2015). "Gran Toba: la reconstrucción de un barrio emblemático", Resistencia.

Registro fotográfico de diario Norte. 